\title{
Phytochemical composition and antioxidant capacity in Mexican pecan nut
}

\author{
María Antonia Flores-Córdova1', Esteban Sánchez ${ }^{1 *}$, Ezequiel Muñoz-Márquez', Damaris Lepoldina Ojeda-Barrios², \\ Juan Manuel Soto-Parra ${ }^{2}$, Pablo Preciado-Rangel ${ }^{3}$
}

${ }^{1}$ Centro de Investigación en Alimentación y Desarrollo A. C. Avenida Cuarta Sur Fraccionamiento Vencedores del Desierto. Cd. Delicias, Chihuahua, México. ${ }^{2}$ Facultad de Ciencias Agrotecnológicas, Universidad Autónoma de Chihuahua, Chihuahua. México. ${ }^{3}$ Instituto Tecnológico de Torreón, Torreón, Coahuila. México

\section{A B S T R A C T}

The nut is a very nutritious fruit, and they play an important role in the nutrition of humans, because it is an important source of antioxidants and natural phenol compounds. It has been shown that such compounds are able to reducing the risk to get chronic diseases. This study evaluates the content in phenolic compounds and the antioxidant activity in pecan edible part and shell, examining the two varieties Western and Wichita, cultivated in the region of Delicias of the state of Chihuahua (Mexico). The high concentrations of phenolic compounds $\left(170.36 \mathrm{mg} \mathrm{g}^{-1}\right)$ and tannins $\left(582.07 \mathrm{mg} \mathrm{g}^{-1}\right)$ found in the shell were 7 - to 8 -fold higher than in the edible part. The results for the variety Wichita were significantly higher than for Western. The antioxidant activity was assessed by the DPPH ${ }^{*}$ method $(1,1$-diphenyl1,2-picrylhydrazyl), which correlated strongly with the phenolic compounds $\left(r^{2}=0.99\right)$. Using liquid chromatography (HPLC) three phenolic compounds could be identified in the edible part and shell of the pecan nut, which were, gallic acid, ellagic acid, and catechin, while only ellagic acid was not identified in the shell of the variety Western. Pecans are rich in phytochemical compounds that provide high antioxidant activity to the edible part and the shell. These compounds are of great importance for the health of the people. The high concentration of phytochemicals in the shells represents a good source of antioxidants for future applications in the pharmaceutical and agro-food industry.

Keywords: Carya illinoiensis; Antioxidants; Bioactive compounds; Phytonutrients; Pecan nut

\section{INTRODUCTION}

Recently, the consumption of nuts has increased due to growing interest in a healthy lifestyle, given that several studies suggest a connection between the frequent consumption of nuts and a lower incidence of heart disease, obesity, and type-II diabetes (Luna-Guevara et al., 2010). In addition to being rich in proteins, vitamin E, unsaturated fatty acids and fibers, nuts are an important source of numerous phytochemicals, including phenolic compounds with natural antioxidant capacity (Kornsteiner et al., 2009), which have attracted considerable attention in recent years due to their many health benefits, including anti-inflammatory and anti-cancer properties (Chen and Blumberg 2008). Therefore, great interest has arisen in characterizing and quantifying phenolic compounds of the edible part, classified among the foods with high antioxidant capacity (John and Shahidi, 2010), and byproducts such shells rich in phenolic compounds and in flavonoids (e.g. proanthocyanidins) (Pinheiro do Prado et al., 2014). Some authors have recently demonstrated that the pecan shell has higher levels of phenols and tannins than in the edible part and that these phytochemical compounds are related to antioxidant properties (Trevisol et al., 2011). On the other hand, an important group of phenolic compounds are tannins, which are found in a condensed and hydrolyzed form. These molecules are of notable nutritional and medicinal value due to their potent antioxidant capacity (Pinheiro do Prado et al., 2009). The antioxidant activity, resulting from the presence and chemical structure of the polyphenols, has attracted interest in the possible beneficial effects for human health of food rich in polyphenols. Antioxidants protect the body from free radicals, molecules which are highly reactive and can damage the body at the cellular level, increasing the risk of cardiovascular disease (Padilla et al., 2008). Therefore, it is of great interest to characterize the natural phytochemical content and antioxidant capacity of the pecan.

\footnotetext{
${ }^{*}$ Corresponding author:

Esteban Sánchez, Centro de Investigación en Alimentación y Desarrollo A.C. Unidad Delicias. Av. Cuarta Sur 3820, Fracc. Vencedores del Desierto. Cd. Delicias, Chihuahua. México. C.P. 33089. E-mail: esteban@ciad.mx
} 
The pecan a widely popular food and an economically important crop in the United States and Mexico. However, regarding the edible part, very few studies have been published on the phytochemicals and health benefits of this nut (De la Rosa et al., 2011). A study made in 10 European countries demonstrated that women who consumed more than $6.2 \mathrm{~g}$ of nuts daily reduced the risk of colon cancer by 31\% (Zhiping et al., 2011). For this reason, studies are needed to provide current data on the composition and concentration of the phenolic components of different crops.

The aim of the current study is to evaluate the phytochemical composition and antioxidant activity of the edible part and shell of the pecan varieties Western and Wichita, which are being grown in the southwest region of Delicias, Chihuahua, Mexico.

\section{MATERIALS AND METHODS}

\section{Plant material and experimental design}

The plant material was provided by Rancho Santa Teresita, located at $\mathrm{km} 86.4$, of the municipality of Delicias, Chihuahua (Mexico). The two varieties studied were Western and Wichita because of their commercial importance. Pecan nuts from the 2014 harvest were taken to the Plant Physiology and Nutrition Laboratory of Center for Food Research and Development, where the nuts were mechanically shelled. The shells were separated from the edible part and subsequently milled in a food processor and stored in plastic bags at $-4^{\circ} \mathrm{C}$ until used. For the analysis, the samples were dried in a Felisa air oven at $40^{\circ} \mathrm{C}$.

\section{Determination of the phytochemical compounds}

The nuts were milled in a food processor and then the fat was removed according to the methodology established by Villareal-Lozoya et al. (2007) with slight modifications. Afterwards the samples were vacuum filtered at $35^{\circ} \mathrm{C}$ and stored until analyzed. The samples of pulverized shell and the combustible part were homogenized with $5 \mathrm{~mL}$ of methanol, $5 \mathrm{~mL}$ of chloroform, and $2.5 \mathrm{~mL}$ of and $\mathrm{NaCl}$ solution at $1 \%$. For quantification of the desired compounds, the sample and the reagents were completely homogenized, then the solution was passed through a No. 601-15 cm Ahlstrom ${ }^{\circledR}$ filter, and centrifuged for 10 minutes at $8273.20 \mathrm{~g}$.

\section{Quantification of total phenols}

The phenolic content was quantified according to the technique developed by Singleton and Rossy in 1965. $1.5 \mathrm{~mL}$ of calcium carbonate ( $\mathrm{Na} 2 \mathrm{NO} 3$ ), $0.5 \mathrm{~mL}$ of $50 \%$ Folin-Crocalteu, $2.75 \mathrm{~mL}$ of deionized water and $0.5 \mathrm{~mL}$ of sample extract were placed; Mixed in a test tube. After the sample was incubated for one hour at room temperature, a calibration curve was made with gallic acid, which was taken as the basis for the quantification of total phenols, by measuring its level of absorbance in a Genesys 10s UV/Vis spectrophotometer Thermo Scientific.

\section{DPPH antioxidant capacity}

The antioxidant capacity was determined by the method of Kim et al. (2002), based on the absorbance measurement of the radical DPPH (1,1-diphenyl-1,2-picryohydrazyl). This compound is a stable radical that has an intense violet color and absorbs radiation at $517 \mathrm{~nm}$, so that its concentration can be determined by spectrophotometric methods. The reaction is made on mixing $3.9 \mathrm{~mL}$ of solution of the radical DPPH with $0.1 \mathrm{~mL}$ of plant extract. The mixture remained for 30 minutes in the light and room temperature. then, was measured at 517 nanometers in UV/Vis spectrophotometer. For the white setting $80 \%$ methanol was used. The analysis was made in triplicate and the results were expressed as $\mathrm{mg}$ TEAC $\mathrm{g}^{-1}$ (Trolox equivalent antioxidant activity) of dry weight based on a calibration curve of Trolox.

\section{Quantification of condensed tannins}

In this case, $1 \mathrm{~mL}$ of the extract was added to $4 \mathrm{~mL}$ of an $\mathrm{HCl}$ solution at $8 \%$ in $\mathrm{MeOH}(\mathrm{v} / \mathrm{v})$ and a vanillin solution in $\mathrm{MeOH}$ at $4 \%(\mathrm{v} / \mathrm{v})$ at a proportion of $1: 1$. The solution was measured at $500 \mathrm{~nm}$ in a UV/Vis spectrophotometer after being passed through a water bath for 20 minutes at $30^{\circ} \mathrm{C}$, using a catechin calibration curve. The total tannin content was expressed as $\mathrm{mg}$ equivalents of catechin in dry weight of the sample (mg EC g ${ }^{-1}$ ) (Price et al. 1978).

\section{Identification and quantification of phenolic compounds by LC-MS}

To carry out the quantification of the compounds, $100 \mathrm{~g}$ of the sample were used and the extraction was carried out with methanol $(3 \times 0.4 \mathrm{~L}-1)$ at room temperature for $24 \mathrm{~h}$. After the dry extract was obtained, it was dissolved in methanol and passed through a Nylon membrane type MNYL, $0.2 \mu \mathrm{m}$ (Hernández et al. 2007). which was determined with an Agilent 1100 Tramp LC/MSD system (Palo Alto, CA, USA), using a column and a LIchrospher detector of 100 diodes (DAD). Formic acid was used to elute the column. For the mobile phase, $5 \%$ formic acid was added in water and methanol. A gradient program of $30 \%$ B (0-15 min), 40\% (15-20 min), 45\% B (20-30 min), 50\% B (30-50 min), 80\% (50 -65 min), and 100\% B (65-75 min). The elution was presented at 280 and $340 \mathrm{~nm}$, with a spectrum register of 190 and $400 \mathrm{~nm}$. The parameters were operated with a voltage of $5 \mathrm{Kv}$ and a $350^{\circ} \mathrm{C}$ temperature. The shell and almond samples were dissolved in $5 \mathrm{mg} \mathrm{ml}^{-1}$ of methanol, then filtered using a nylon membrane (type MNYL, $0.2 \mu \mathrm{m}$, Whatman, once the compound was obtained, 20 ul were taken and injected into The HPLC system, and in the absorption spectra obtained. The peaks 
of the present compounds were determined and quantified from the calibration curves of the chromatograms.

\section{Statistical analysis}

The data were submitted to an analysis of variance and Tukey's test for each mean comparison. The correlation between variables was evaluated by the Pearson coefficient, at a significance level of $\mathrm{p}<0.05$, using SAS ${ }^{\circledR}$ (Statistical Analysis System) version 9.0 (SAS) (SAS 2002). The experimental design was completely random with four replicates.

\section{RESULTS AND DISCUSSION}

\section{Phenolic compounds}

The fact that many fruits contain phenolic compounds has attracted public attention as well as scientific interest due to the health benefits of antioxidant effects (Zhiping et al., 2011). The total phenolic content (TP) was significantly $(p<0.05)$ affected by cultivar. Fig. 1 shows the phenolic compound concentrations found in the edible part and shell of pecan, expressed as mg of gallic acid (GA). The highest concentrations were found in shells, values being 7- or 8-fold higher than in the edible part. In the variety Wichita, values reached $23.13 \mathrm{mg} \mathrm{g}^{-1}$ and $170.36 \mathrm{mg} \mathrm{g}^{-1}$ in the edible part and shell, respectively, and in Western, $19.25 \mathrm{mg}$ $\mathrm{g}^{-1}$ and $145.44 \mathrm{mg} \mathrm{g}^{-1}$, respectively. Lombardi et al. (2009) reported values of 62 to $106 \mathrm{mg} \mathrm{g}^{-1}$ in edible part of the variety Kanza. Padilla et al., 2008 and Pinheiro do Prado et al. 2009 registered 11.8 to $20.1 \mathrm{mg} \mathrm{g}^{-1}$ in pecan edible part and 117 to $167 \mathrm{mg} \mathrm{g}^{-1}$ in the shell, the latter coinciding with the values found in the present study. According to the values for the edible part, the variability is probably due to the different varieties investigated, kanza, Nacono, Pawnee, Shawnee, Desirable, Barton, Choctaw and Cape Fear, their geographic origin, year of harvest, soil, agricultural practices, and environmental factors.

In the present study, the variety Wichita cultivated in the region of Delicias, Chihuahua (Mexico), presented the highest concentrations both in the edible part as well as in the shells, while the lowest concentrations corresponded to the variety Western. According to the studies performed, statistically the total phenol concentrations were affected ( $p<0.05$ ), indicating that the proportions determine the possible health benefits, which may vary according to the pecan variety. These benefits are related to the phenolic content in gallic and ellagic acids present in the edible part and shell of the pecan.

\section{Antioxidant capacity}

Several studies in different regions of the world and over the years, have made known to the population the health benefits of nut consumption, due to the antioxidant compounds they contain (Chen et al., 2013). Antioxidant capacity of the varieties Western and Wichita was evaluated using the free radical DPPH, with significant differences $(p>0.05)$ in all the varieties evaluated (Fig. 2). The variety Wichita had the highest values, with $137.21 \mathrm{mg}\left(\mathrm{TEAC} / \mathrm{g}^{-1}\right)$ for the pecan edible part and $467.54 \mathrm{mg}\left(\mathrm{TEAC} / \mathrm{g}^{-1}\right)$ for the shell, while the lowest corresponded to the variety Western. Pinheiro do Prado et al. (2013) evaluating the antioxidant capacity of shell, found values of 346.47 to $612.24 \mathrm{mg}$ TEAC $/ \mathrm{g}^{-1}$, similar to those found in the present study. In pecan edible part, Yang et al. (2009) found $427.0 \mu \mathrm{mol} \mathrm{g}^{-1}$ Vit C. The antioxidant activity was consistently greater in the shell than in the edible part, in agreement with many authors who have found that the by-products such as pecan shells are rich in phytochemical compounds with a high antioxidant capacity, in contrast to pecan edible part (Pinheiro do Prado et al., 2004; De la Rosa et al., 2011), and therefore the antioxidant capacity observed implies that phenolic compounds present in the varieties have a greater capacity to stabilize free radicals. This high capacity in the shell offers an alternative use for the pecan shell as a new source of antioxidants. Blomhoff et al. (2006) observed

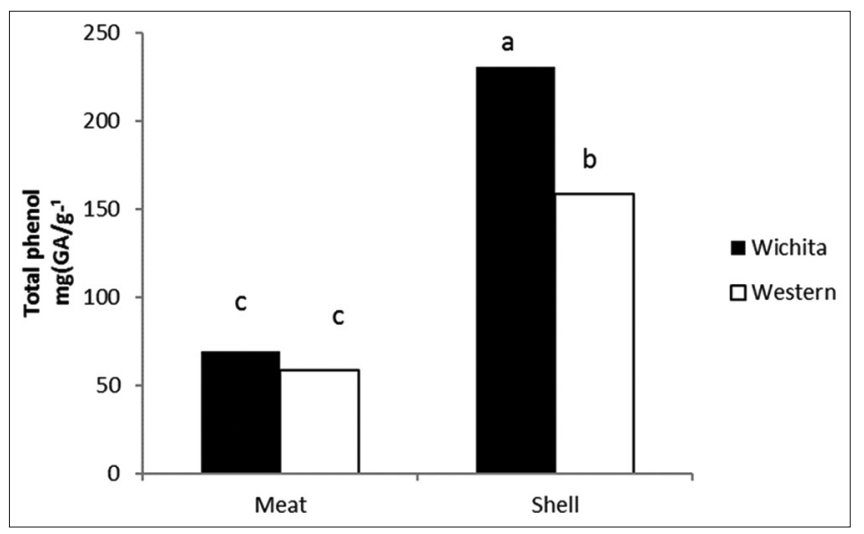

Fig 1. Total phenol concentration in the edible part and shell of the two pecan varieties studied. ${ }^{a-c}$ Different letters indicate statistical difference $(p \leq 0.05)$.

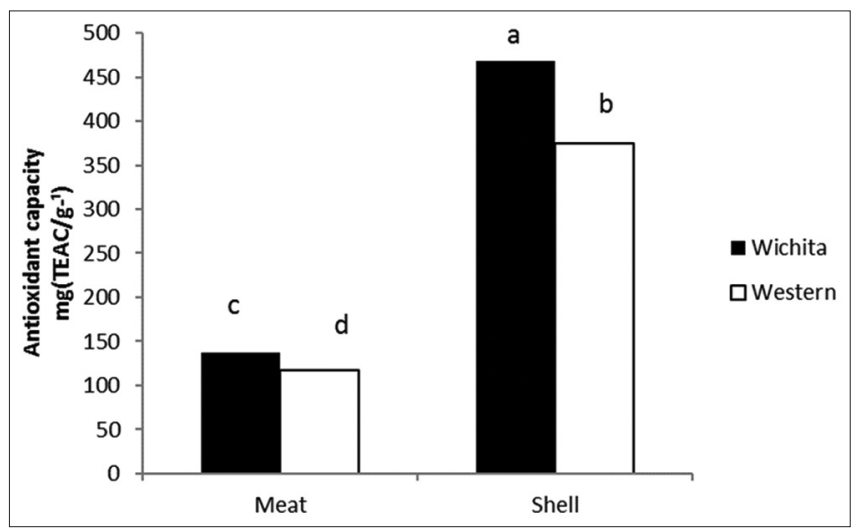

Fig 2. Antioxidant capacity in the edible part and shell of two pecan varieties. ${ }^{a-d}$ Different letters indicate statistical difference $(p \leq 0.05)$. 
that pecans contain a massive quantity of antioxidants and are far superior in values to foods of animal origin such as edible part, cheese, or milk, Which possess biochemical activities that minimize the progression of chronic diseases, including antiinflammatory and antioxidant activities, as well as the capacity to promote the carcinogenic detoxification, to reduce cell proliferation, and/or reduce LDL-cholesterol (Chen and Blumberg, 2008). A high antioxidant activity is due to the content of phenolic compounds of pecans, combined with other properties (Abbasi et al., 2010).

Furthermore, strong correlations were found between the antioxidant capacity determined by DPPH and the phenolic content in the edible part and shell $\left(\mathrm{r}^{2}=0.99\right)$. The total phenolic content correlated well with the antioxidant activity, is more polyphenols, higher the antioxidant capacity, the greater the antioxidant activity. These results suggest that the consumption of products such as nuts can have the same beneficial effects for health. This means, the shell constitutes a raw material to derive natural antioxidants for use in the food industry. In fact, synthetic antioxidants such as butylated hydroxytoluene are commonly used in the food industry, although these synthetic compounds have been demonstrated to have a toxicity and risk of possible carcinogenic effects (Feng-Lin et al., 2010). Therefore, it is of great importance to find new sources of antioxidants of natural origin, such as nutshells.

\section{Condensed tannins}

The condensed tannins were quantified by means of the vanillin test. With this technique, values ranged from 21.81 to $23.22 \mathrm{mg} \mathrm{CE} \mathrm{g}^{-1}$ in the edible part and from 432.86 to $528.07 \mathrm{mg} \mathrm{CE} \mathrm{g}^{-1}$ in the pecan shell. While the total condensed tannins were significantly affected by variety in the shell (Fig. 3), no significant differences were found in the edible part. The highest values were presented by the Wichita variety, while the Western one showed lower values. Zhiping et al., (2011) registered values of $13.21 \mathrm{mg} \mathrm{CE} \mathrm{g}^{-1}$ for tannins in pecan edible part; meanwhile Pinheiro do Prado et al., (2009, 2014), for tannins of different varieties found 1 to $43 \mathrm{mg} \mathrm{CE} \mathrm{g}^{-1}$ in the edible part and 36.94 to $412.1 \mathrm{mg} \mathrm{CE} \mathrm{g}^{-1}$ in the shell. Villareal-Lozoya et al. (2007) found values of 388 to $876 \mathrm{mg} \mathrm{CE} \mathrm{g}^{-1}$ in shell and $23 \mathrm{a}$ $47 \mathrm{mg} \mathrm{CE} \mathrm{g}^{-1}$ in the edible part, showing similar values to those of the present work. Previous studies evaluating tannins found a high shell values in relation to those of the edible part. This supports the contention that the pecan shell is a rich source of natural tannins and could be offer different uses in the pharmaceutical and food industries.

\section{Identification and quantification of individual phenolic compounds}

Three phenolic compounds were identified in the samples of the pecan edible part and shell (Table 1). The presence

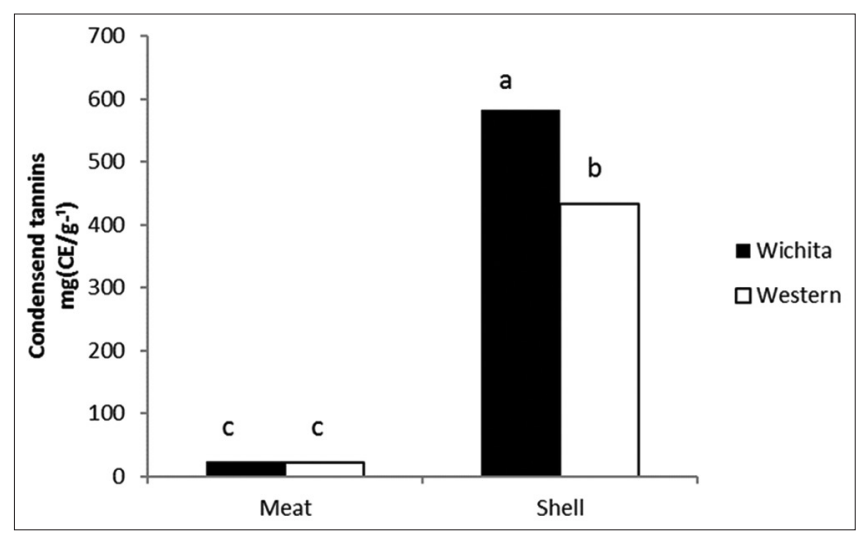

Fig 3. Concentration of condensed tannins, in the edible part and shell of two pecan varieties. ${ }^{a-c}$ Different letters indicate statistical difference $(p \leq 0.05)$.

Table 1: Concentration of phenolic compounds found in pecan edible part and shell of the two varieties Western and Wichita

\begin{tabular}{lccc}
\hline \multicolumn{4}{c}{ Pecan edible part g kg-1 } \\
\hline Wichita & Gallic acid & Ellagic acid & Catechin \\
Western & $1.03 \pm 0.47^{\mathrm{a}}$ & $0.214 \pm 0.01^{\mathrm{a}}$ & $0.408 \pm 0.02^{\mathrm{a}}$ \\
& $0.56 \pm 0.18^{\mathrm{b}}$ & $0.069 \pm 0.02^{\mathrm{c}}$ & $0.305 \pm 0.07^{\mathrm{b}}$ \\
Wichita & \multicolumn{2}{c}{ Pecan shell g kg-1 } \\
Western & $0.191 \pm 0.03^{\mathrm{c}}$ & $0.142 \pm 0.04^{\mathrm{b}}$ & $0.158 \pm 0.03^{\mathrm{d}}$ \\
\hline
\end{tabular}

${ }^{*} \mathrm{Nd}$ not detected ${ }^{\mathrm{a}-\mathrm{d} D}$ ifferent letters indicate statistical difference $(p \leq 0.05)$

of certain chemical components were found in each edible part and shell sample, but in the Western variety, no ellagic acid was detected. Thus, significant differences $(p<0.05)$ were detected in the two varieties evaluated. Wichita presented the highest values in the three compounds evaluated present in the edible part, with gallic acid having the highest concentration $\left(1.03 \mathrm{~g} \mathrm{~kg}^{-1}\right)$. In the shell, the variety Wichita also presented the highest values, except for the compound catechin.

Villareal-Lozoya et al., 2007 reported the presence of gallic acid of between 651 and $1300 \mu \mathrm{g} \mathrm{g}^{-1}$ while ellagic acid was between 2.505 and $4.732 \mu \mathrm{g} \mathrm{g}{ }^{-1}$. De la Rosa et al. (2011) found quantities of $1.4-1.7 \mathrm{mg}$ of free EA $\mathrm{g}$ and 4.6 to $5.5 \mathrm{mg}$ of total EA $\mathrm{g}$ and of Gallic acid of 64.3 to 69.3 in the free form and 189.0 to $274.5 \mathrm{~g} \mathrm{~g}^{-1}$ in the total form. Robins et al. (2015) registered values of 1.892 to $2.62 \mathrm{eq}$ $\mathrm{kg}^{-1}$ of ellagic acid. Although all of these studies were made in pecan edible part, the data reported in the literature are expressed with different units and varieties. For this reason, comparisons are difficult, despite that all the data indicate that the pecan is a good source of ellagic and gallic acid. On the other hand, in studies published by Pinheiro et al. In 2014, found concentrations ranging from 124.26 to $828.68 \mathrm{~g} \mathrm{~mL}-1$ of gallic acid in the shell. However, few studies on the pecan nut shell phenolic composition have been published, and therefore the data from the present 
study offer a good source of information for future studies about this interesting topic.

\section{CONCLUSIONS}

From the present study, it is concluded that pecans are rich in phenolic compounds, condensed tannins, and mainly hydrolysable tannins, such as gallic and ellagic acid, and catechin, due to the presence of them the pecans have high antioxidant activity against several free radicals. The concentration in phenolic compounds and antioxidant activity was about 7 - to 8 -fold higher in the shells than in the edible part, and depended on type of pecan, with the variety Wichita having the highest concentrations of phytochemical compounds.

\section{Authors contributions}

All authors contributed extensively to the work presented in this article. M.A.F.C. and E.S.: Designed and performed research, wrote and revised the manuscript. M.A.F.C. and E.M.M.: Contributed to the development of experimental part. D.L.O.B. and P.P.R.: Performed chemical analyses and reviewed the manuscript. J.M.S.P.: Performed statistical analysis and helped in data interpretation and discussion. All authors read and approved the final manuscript.

\section{REFERENCES}

Abbasi, M. A., A. Raza, T. Riaz, T. Shahzadi, A. Rehman, M. Jahangir, D. Shahwar, S. Z. Siddiqui, A. R. Chaudhary and N. Ahmad. 2010. Investigation on the volatile constituents of Juglans regia and their in vitro antioxidant potential. Proc. Pak. Acad. Sci. 47: 137-141.

Blomhoff, R., M. H. Carlsen, L. F. Andersen and D. R. Jacobs. 2006. Health benefits of nuts: Potential role of antioxidants. Br. J. Nutr. 96: S52-S60.

Chen, L., X. Xin, H. Zhang and Q. Yuan. 2013. Phytochemical properties and antioxidant capacities of commercial raspberry varieties. J. Funct. Foods. 5: 508-515.

Chen, O. and B. J. Blumberg. 2008. Phytochemical composition of nuts. Asia Pac. J. Clin. Nutr. 17: 329-322.

De la Rosa, L., E. Álvarez-Parilla and F. Sharidi. 2011. Phenolic compounds and antioxidant activity of kernels and shells of Mexican pecan (Carya illinoinensis). J. Agric. Food Chem. 59: 152-162.

Feng-Lin, S., G. Ren-You, Z. Yuan, X. Qin, K. Lei and L. Hua-Bin. 2010. Total phenolic contents and antioxidant capacities of selected Chinese medicinal plants. Int. J. Mol. Sci. 11: 2362-2372.

Hernández, J., F. M. Goycoolea, J. Quintero, A. Acosta, M. Castañeda, Z. Domínguez, R. Robles, L. Vázquez-Moreno, F. E. Velázquez, H. Astiazaran, E. Lugo and C. Velázquez. 2007. Sonoran propolis: Chemical composition and antiproliferative activity on cancer cell lines. Planta Med. 73: 1469-1474.

John, J. A. and F. Shahidi. 2010. Phenolic compounds and antioxidant activity of Brazil nut (Bertholletia excelsa). J. Funct. Foods. 2: 196-209.
Kim, D. O., K. W. Lee, H. J. Lee and C. Y. Lee. 2002. Vitamin C equivalent antioxidant capacity (VCEAC) of penolics phytochemicals. J. Agric. Food Chem. 50: 3713-3717.

Kornsteiner, M., K. H. Wagner and I. Elmadfa. 2009. Tocopherols and total phenolics in 10 different nut types. Food Chem. 98: 381-387.

Lombardi, L., J. E. Villareal-Lozoya and L. Cisneros-Zevallos. 2009. Antioxidant properties of pecan kernels. Acta Hortic. 841: 91-96.

Luna-Guevara, J. J. and J. A. Guerrero-Beltrán. 2010. Algunas características de compuestos presentes en los frutos secos y su relación con la salud. Temas Selectos Ing. Alimentos. 4: 37-48.

Padilla, A. M., L. Rincón and L. Boud-Rached. 2008. Contenido de polifenoles y actividad antioxidante de varias semillas y nueces. Arch. Latinoam. Nutr. 58: 303-308.

Pinheiro do Prado, A. C., B. A. Manion, K. Seetharaman, F. C. Deschamps, A. D. Barrera and B. J. Mara. 2013. Relationship between antioxidant properties and chemical composition of the oil and the shell of pecan nuts (Carya illinoinensis (Wangenh) C. Koch). Ind. Crops Prod. 45: 64-73.

Pinheiro do Prado, A. C., A. A. Monalise, R. Fett and B. J. Mara. 2009. Antioxidant properties of pecan nut (Carya illinoinensis (Wangenh.) C. Koch) shell infusion. Grasas y Aceites. 60: 330-335.

Pinheiro do Prado, A. C., A. A. Monalise, R. Fett and B. J. Mara. 2009. Phenolic compounds and antioxidant activity of pecan (Carya illinoinensis (Wangenh.) C. Koch) kernel cake extracts. Grasas y Aceites. 60: 458-467.

Pinheiro do Prado, A. C., H. Silvestre da Silva, S. Mello da Silveira, B. P. L. Manique, V. C. R. Werneck, M. Maraschin, F. S. R. Salvador and B. J. Mara. 2014. Effect of the extraction process on the phenolic compounds profile and the antioxidant and antimicrobial activity of extracts of pecan nut [Carya illinoinensis (Wangenh) C. Koch] shell. Ind. Crops Prod. 52: 552-561.

Price, M. L., S. Van Scoyoc and L. G. Butler. 1978. A critical evaluation of the vanillin reaction as an assay for tannin in Sorghum. J. Agric. Food Chem. 26: 1214-1218.

Robbins, K. S., Y. Gong, L. M. Wells, P. Greenspan and R. B. Pegg. 2015. Investigation of the antioxidant capacity and phenolic constituents of U.S. pecans. J. Funct. Foods. 15: 11-22.

SAS. 2002. SAS/STAT users guide: Statics, Version. 9.00. SAS Institute, Inc., Cary, NC, USA, p. 503.

Singleton, V. L. and J. Rossi. 1965. Colorimetry of total phenolics with phosphomolybdic-phosphotunstic acid reagents. Am. J. Enol. Vitic. 16: 144-158.

Trevizol, F., D. M. Benvegnú, R. C. S. Barcelos, C. S. Pase, H. J. Segat, D. V. Tironi, G. S. Dolci, N. Boufleur, P. Reckziegel and M. E. Burger. 2011. Comparative study between two animal models of extrapyramidal movement disorders: Prevention and reversion by pecan nut shell aqueous extract. Behav. Brain Res. 221: 13-18.

Villarreal-Lozoya, J. E., L. Lombardini and L. Cisneros-Zevallos. 2007. Phytochemical constituents and antioxidant capacity of different pecan [Carya illinoinensis (Wangenh.) K. Koch] cultivars. Food Chem. 102: 1241-1249.

Yang, J., L. R. Hai and L. Halim. 2009. Antioxidant and antiproliferative activities of common edible nut seeds. Food Sci. Technol. 42: 1-8.

Zhiping, H., F. Maorun and M. Linchun. 2011. Total phenolic condensed tannin and antioxidant activity of four Carya species from China. Afr. J. Biotechnol. 10: 10472-10477. 